\title{
Theatre Design and Digitisation
}

\author{
William Dudley RDI \\ wsdudley@mac.com \\ http://bill-d.cgsociety.org \\ http://gallery.me.com/wsdudley
}

\section{OVERVIEW}

My general theme is the centuries old quest for an illusionistic space that appears bigger than the confines of the theatre stage, yet can contain live actors and be animated. Computers have in the last 15 years, significantly enhanced the possibilities of theatrical spacial illusion, movement and atmosphere, thus allowing theatre practitioners immense freedom in storytelling for a visually sophisticated public.

Some of the topics covered in my talk include:

(i) A brief history of optical developments in Stage Design, in relation to the history of painting: "The Fourth Wall" and how to restore it. True and false perspective. Pepper's Ghost and Vision Gauzes. Chiaroscuro and limited stage depth. "All done by mirrors" - New mirror illusions. Computer driven scene painting.

(ii) The borrowing of theatre scenic techniques by early cinema practitioners - or, "It's payback time": Borrowing back modern cinema's illusionist hardware and software.

(iii) 1990 - A personal transition from traditional art materials to their digital surrogates: The freedom of multiple undoes. The eraser that worked. The cordless digital pencil that you can safely chew. Endless supplies of paint and paper. Watercolours made from 200 layers of colour. The white ground that stays white. The recording of image states.

(iv) 2002 - The transition from 2D to 3D Digital Theatre Design for set, costume and video projection: The dream of walking into one's own painting - at last realised. From a child's computer game to live actors leading audiences over the rooftops of London to Neverland. Live action video composited into CGI environments to digitally boost cast size as in the Royal Shakespeare Company (RSC) Julius Caesar. (v) The technical possibilities of Digital 3D projection: Digital algorithmic pre-distortion lenses. Non-flat, non-rectangular screens. Kinetic screens and digital wallpaper. Circular and spherical screens (a 1930s idea, now made possible). Image projection on water curtains. Smart projector alignment. Multiple projectors creating seamless, immersive movies on all the above types of screen.

(vi) Generating technical drawings from 3D Models: Archaeological work on the 1577 Rose Theatre, Bankside, London, and designing two plays for Shakespeare's Globe nearby.

(vii) Current video project: "Sunday in the Park with George" by Stephen Sondheim, in The Theatre du Chatelet, Paris, April 2013. A musical celebration of the pointillist painter George Seurat: from pointillism into point cloud...

\section{ILLUSTRATIONS}

\subsection{RSC, Julius Caesar}

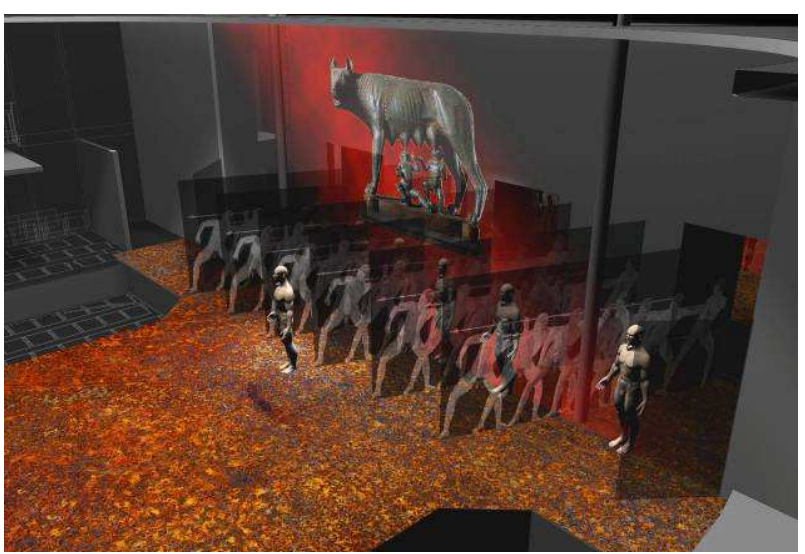

Figure 1. Julius Caesar set for the Royal Shakespeare Company. 


\subsection{Shakspeare's Globe, Titus Andronicus}

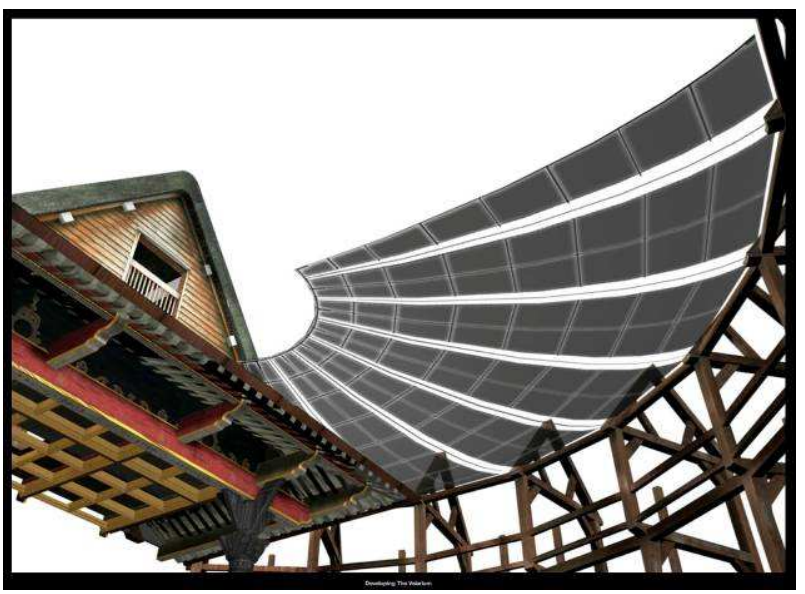

Figure 2. Modelling the velarium, an awning used in the Roman period.

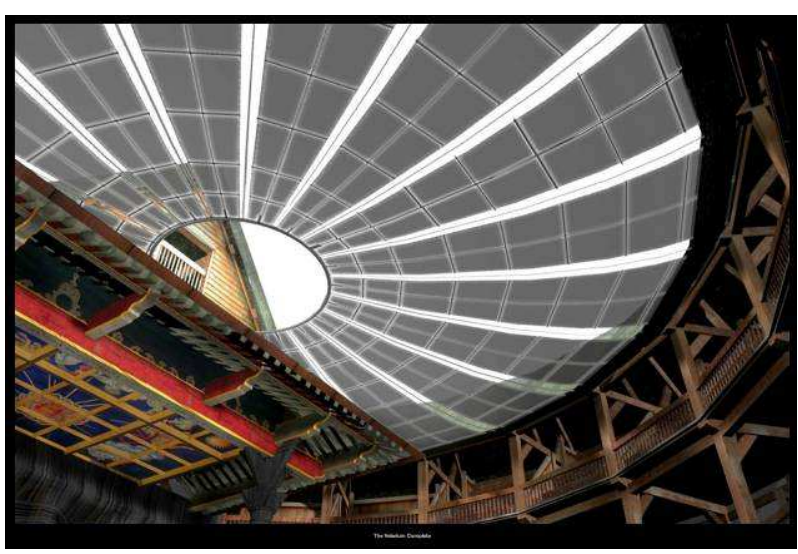

Figure 3. The Globe Theatre model and velarium.

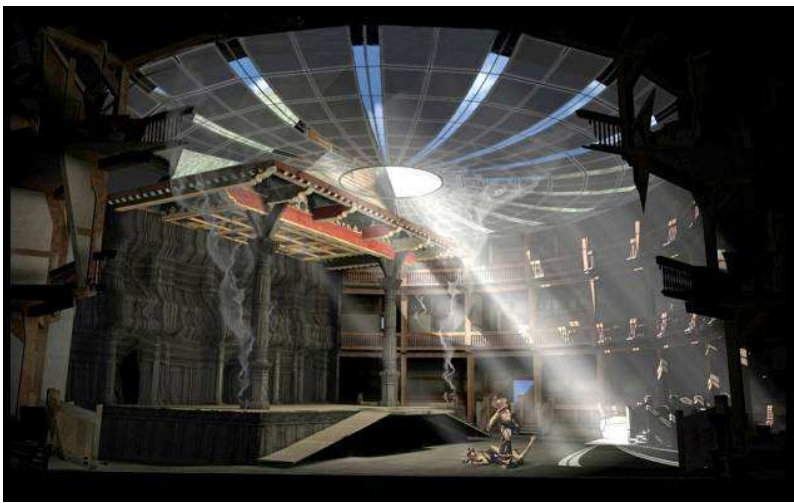

Figure 4. The Globe Theatre as a Roman arena.

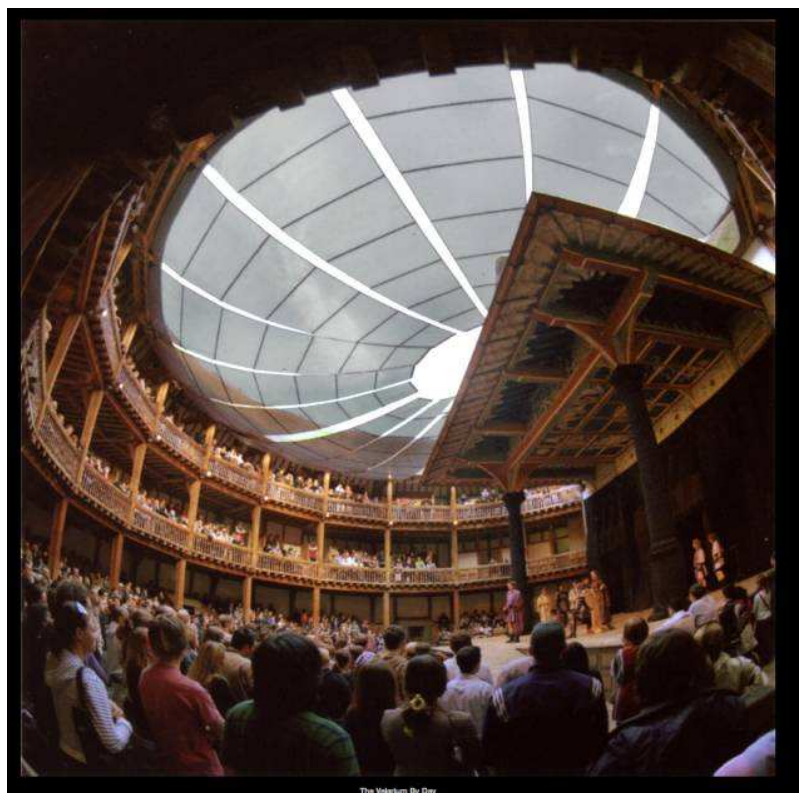

Figure 5. Titus Andronicus in performance at the Globe Theatre.

\subsection{Shakspeare's Globe, Timon of Athens}

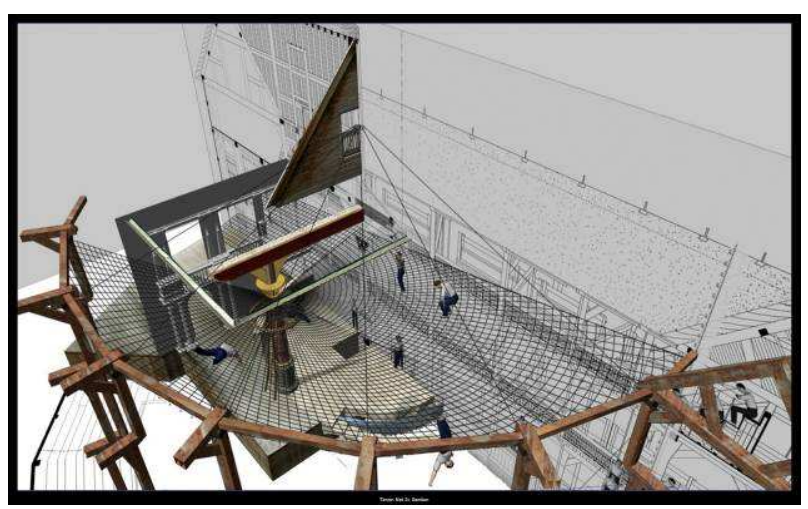

Figure 6. Overhead net design for Timon of Athens.

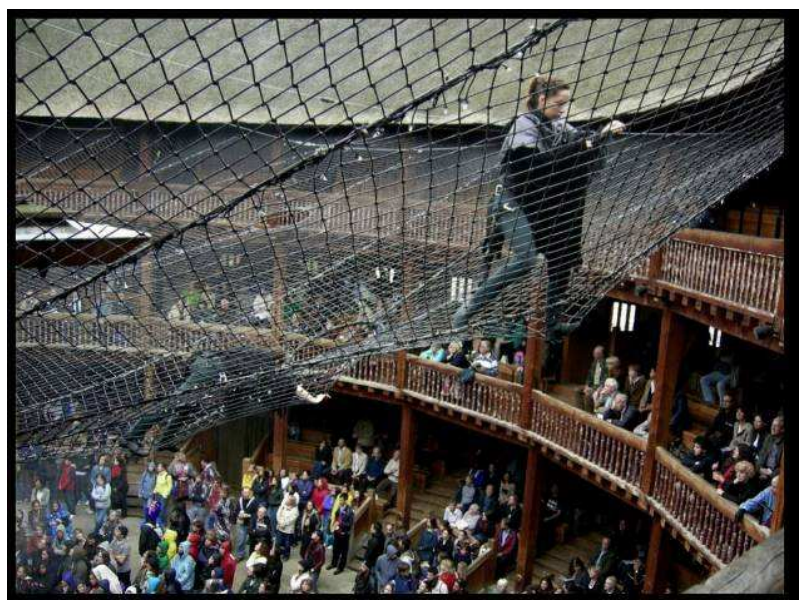

Figure 7. Pre-show safety check of the net. 


\subsection{The Rose Theatre 1587-1605 Exhibition}

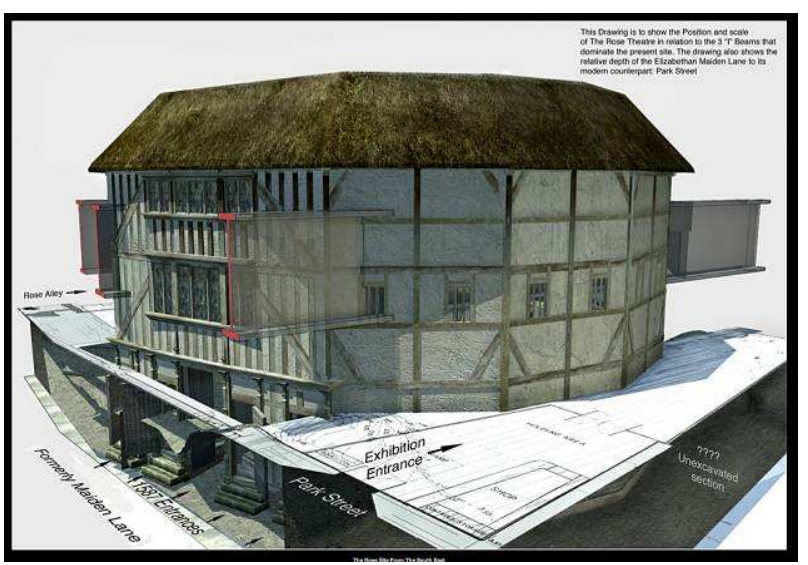

Figure 8. The Rose Theatre reconstruction.

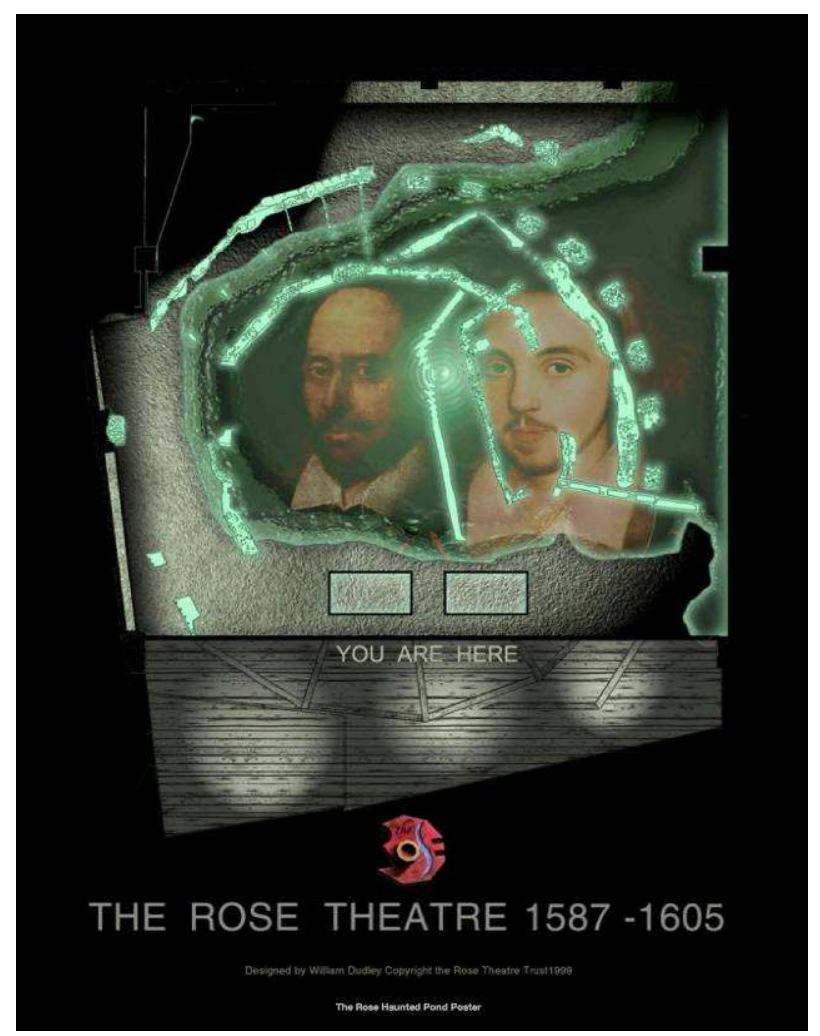

Figure 9. The Rose Theatre 1587-1605 exhibition poster.

\subsection{Peter Pan}

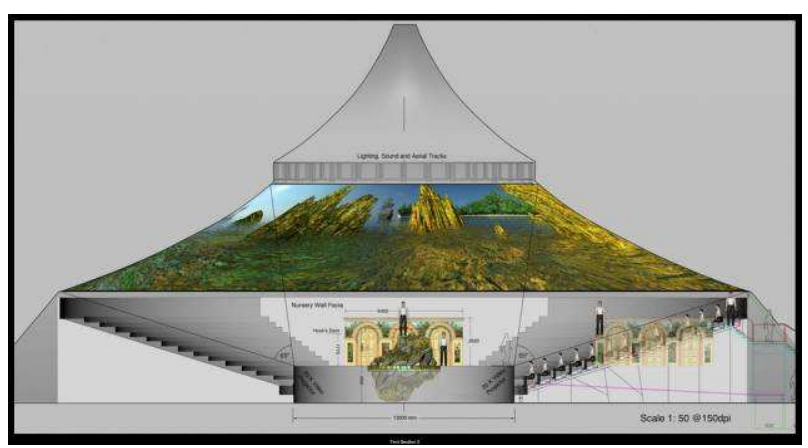

Figure 10. Cross-section of the Peter Pan tent.

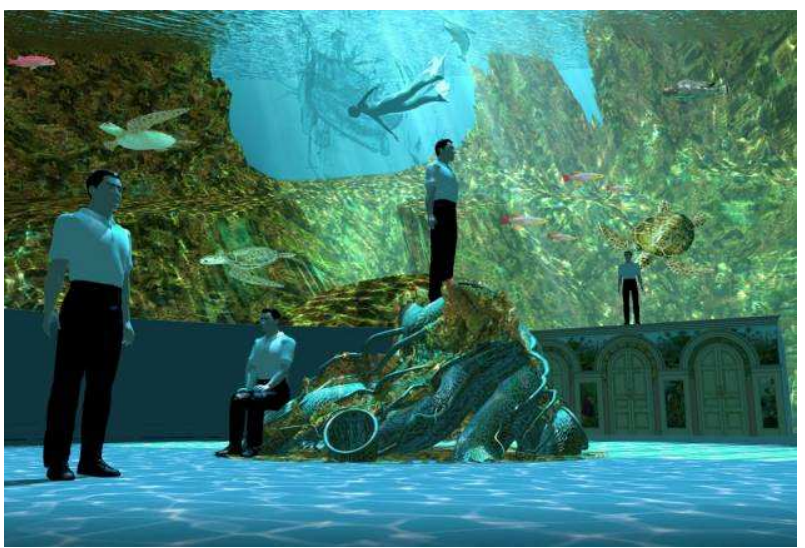

Figure 11. Mermaid's Rock test rendering.

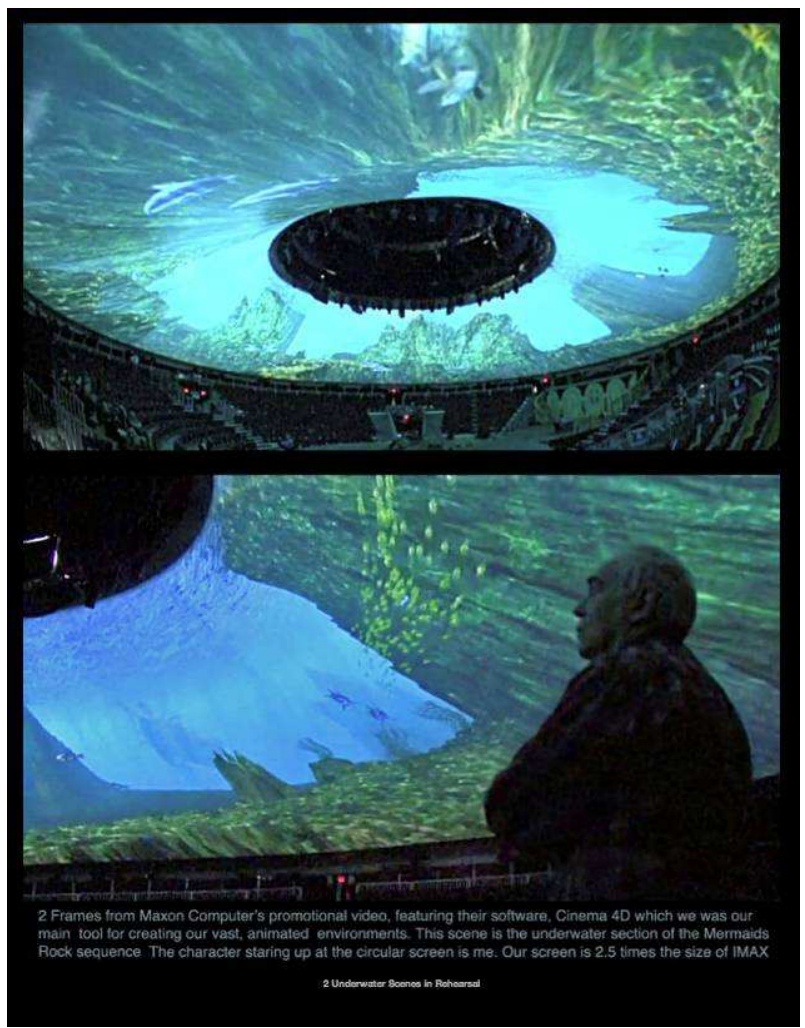

Figure 12. Audience view of Mermaid's Rock. 


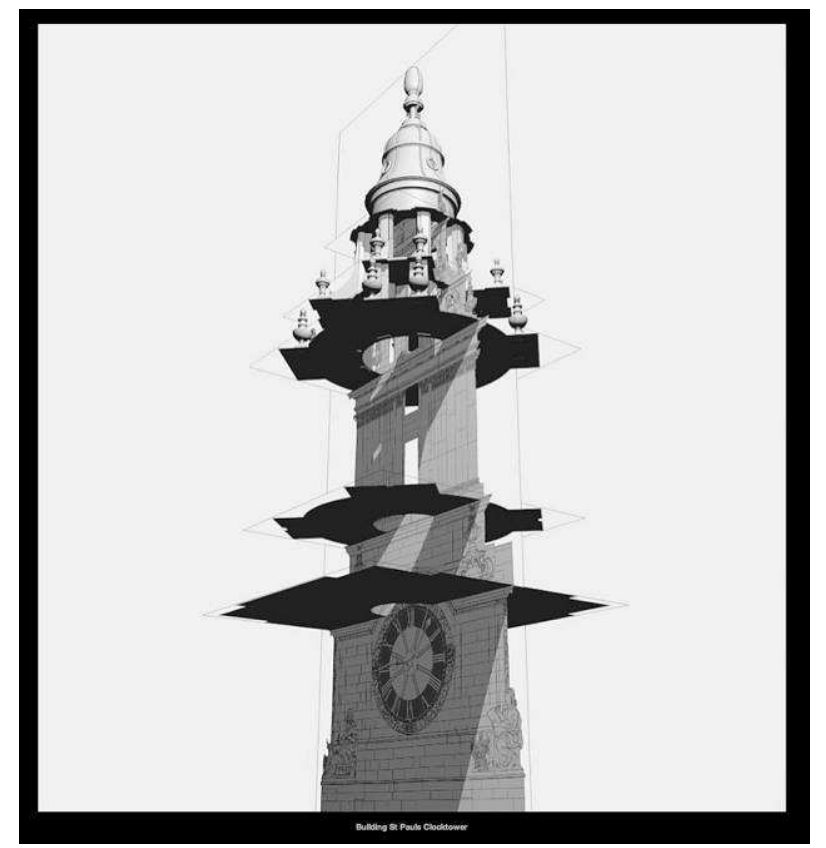

Figure 13. Modelling a St Paul's Cathedral clock tower.

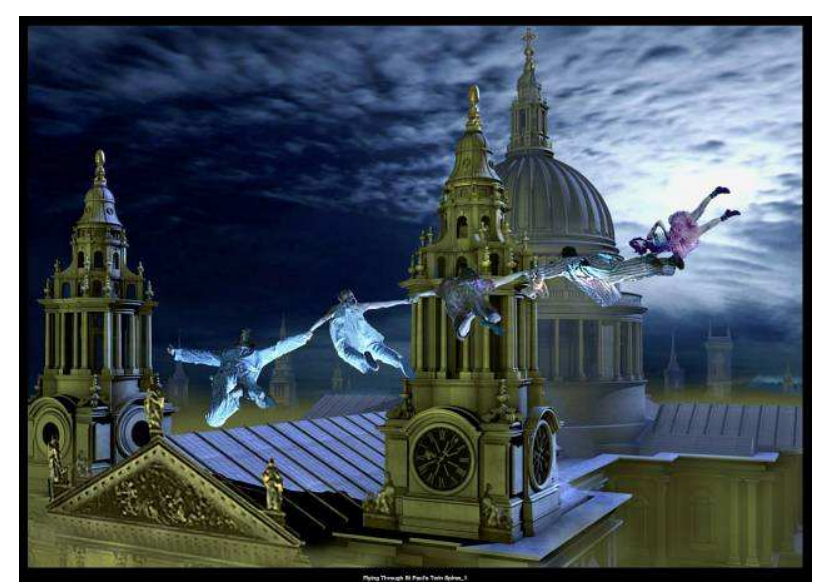

Figure 14. Flying through the St Paul's Cathedral model.

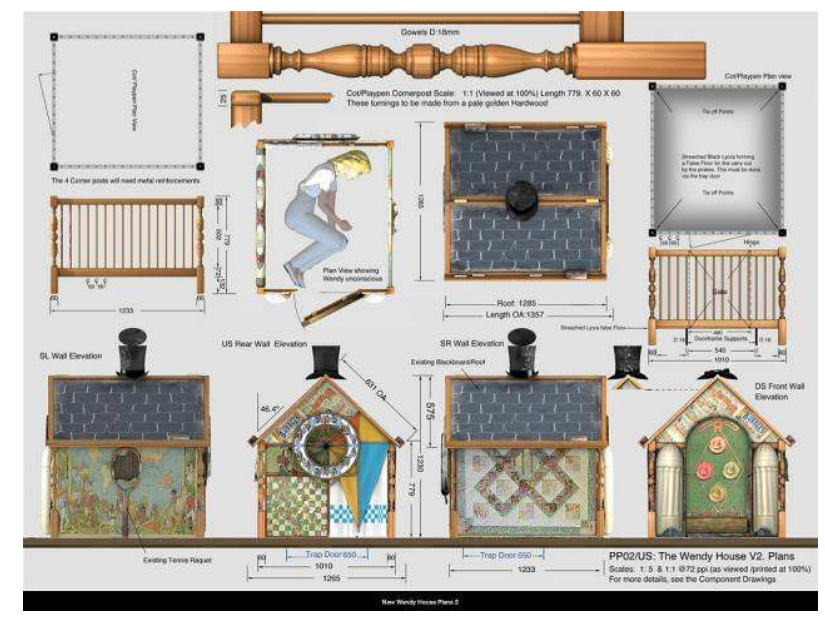

Figure 15. Technical drawing of the Wendy House.

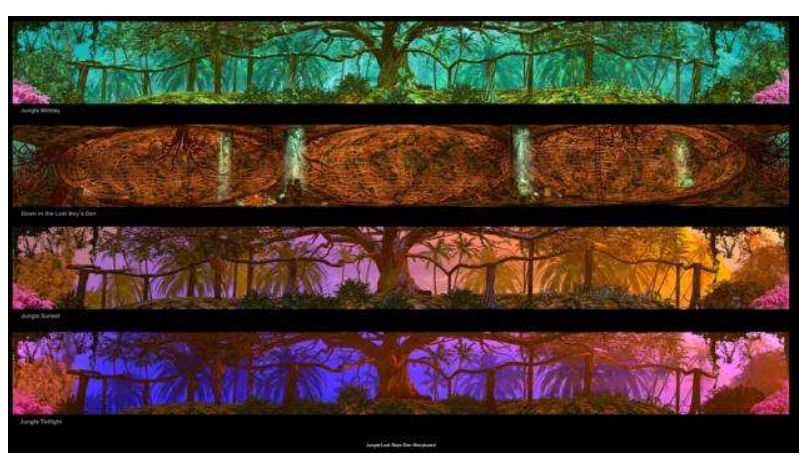

Figure 16. The Lost Boy's Den - jungle storyboard.

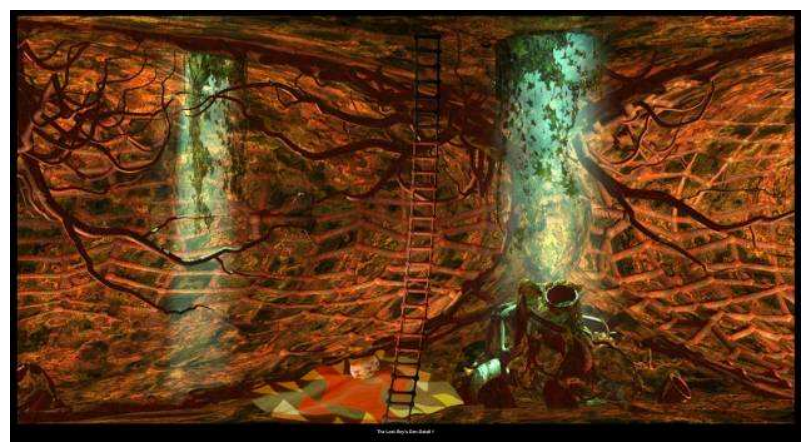

Figure 17. The Lost Boy's Den - detail. 